\title{
Educação em Tempo de Pandemia e a desigualdade social: Considerações do ensino remoto no Estado do Paraná
}

\author{
Solange de Castro* \\ Elisabeth Rossetto**
}

\section{Resumo}

A pandemia originada pela COVID-19 novo agente do Coronavírus (SARS-CoV-2), desencadeou em 2020 alterações no modo de realização das atividades escolares. Considerando as particularidades dessa realidade, o objetivo deste estudo é discutir a implementação do ensino remoto no estado do Paraná. Trata-se de um estudo teórico, buscando apoio nos pressupostos do Materialismo Histórico-Dialético e em autores que permitem compreender as contradições que envolvem a sociedade capitalista e, documental amparando-se no Ofício 040/2020 DEDUC/SEED que rege o planejamento das avaliações escolares. Os resultados apontam que com a implementação desse ensino tem-se agravado a desigualdade social; nem todos têm acesso aos meios utilizados, e o papel do professor adquiriu outro contorno em que o processo ensino aprendizagem tem se dado de maneira fragmentada, isolada, com valorização dos aspectos quantitativos e minimizando a importância do conhecimento.

Palavras-chave: Ensino Remoto. COVID 19. Desigualdade Social. Conhecimento.

http://orcid.org/0000-0002-5142-2217

Universidade Estadual do Oeste do Paraná - UNIOESTE

Mestre pelo Programa de Pós-Graduação em Educação, nível de Mestrado e Doutorado/PPGE - UNIOESTE - Campus de Cascavel. Professora pedagoga e professora de educação especial da Rede Estadual de Ensino do Paraná.

E-mail: solangecastro@escola.pr.gov.br

** http://orcid.org/0000-0002-4581-2446

Universidade Estadual do Oeste do Paraná - Campus de Cascavel.

Doutorado em Educação (UFRGS/RS). Professora associada da Universidade Estadual do Oeste do Paraná - UNIOESTE, Campus de Cascavel.

E-mail: erossetto2013@gmail.com. 


\section{Education in Pandemic Times and social inequality: Deliberations on remote education in the State of Paraná}

\section{Abstract}

The pandemic occasioned by COVID-19, a new Coronavirus agent (SAR$\mathrm{S}-\mathrm{CoV}-2)$, triggered changes in the way school activities were carried out in 2020. Considering the particularities of this reality, the objective of this study is to discuss the implementation of distance learning in the State of Paraná. This is a theoretical study, seeking support in the assumptions of Historical-Dialectic Materialism and in authors who help us to understand the contradictions surrounding the capitalist society and also is documentary based on Office 040/2020 DEDUC/SEED which regulates the planning of school tests. The results show that with the implementation of this method, social inequality has been aggravated; not everyone has access to the mediums used, and the role of the teacher has acquired another contour in which the teaching-learning process has taken place in a fragmented, isolated way, valuing quantitative aspects and minimizing the importance of knowledge.

Keywords: Distance Learning. COVID 19. Social Inequality. Knowledge

\section{Educación en Tiempos de Pandemia y desigualdad social: Consideraciones de la enseñanza remota en el Estado de Paraná}

\section{Resumen}

La pandemia originada por el nuevo agente COVID-19 del Coronavirus (SARS-CoV-2), desencadenó en 2020 cambios en el modo de realización de las actividades escolares. Considerando las particularidades de esta realidad, el objetivo de este estudio es discutir la implementación de la enseñanza remota en el estado de Paraná. Se trata de un estudio teórico, buscando apoyo en los presupuestos del Materialismo Histórico-Dialéctico y en autores que permiten comprender las contradicciones que envuelven a la sociedad capitalista y, documental amparándose en el Oficio 040/2020 DEDUC/SEED que rige la planificación de las evaluaciones escolares. Los resultados apuntan que con la implementación de esa enseñanza se ha agravado la desigualdad social; no todos tienen acceso a los medios utilizados, y el papel del profesor ha adquirido otro contorno en el que 
el proceso de enseñanza aprendizaje se ha dado de manera fragmentada, aislada, con valoración de los aspectos cuantitativos y minimizando la importancia del conocimiento.

Palabras-clave: Enseñanza Remota. COVID 19. Desigualdad Social. Conocimiento

\section{Introdução}

O objetivo deste estudo é discutir e compreender a implementação do ensino remoto em tempo de pandemia no estado do Paraná, a partir da doença causada pelo COVID 19, novo agente do Coronavírus (SARS-CoV-2), que desencadeou no ano de 2020 uma pandemia de escala mundial. Trata-se de um estudo teórico/ bibliográfico a partir do Materialismo Histórico-Dialético, nos debruçando em autores que permitem compreender as contradições que envolvem as políticas na sociedade de classes e em autores que discutem o ensino remoto. Caracteriza-se também como um estudo documental tratando da implementação do ensino remoto no estado do Paraná, priorizando o Ofício 040/2020 DEDUC/SEED que traz sobre o planejamento das avaliações escolares.

Tem-se, de acordo com a literatura utilizada para esse estudo que a educação escolar deve respeitar os princípios da totalidade, da mediação, da consciência, do trabalho e da abstração, na qual sua essência visa a formação humana em suas formas mais complexas. Nessa perspectiva, o conhecimento é considerado o elemento fundamental na transformação da espécie humana em gênero humano. Assim como, a existência humana não é produzida naturalmente, “[...] a produção do homem é, ao mesmo tempo, a formação do homem, isto é, um processo educativo. A origem da educação coincide, então com a origem do homem mesmo". (SAVIANI, 2019, p.35).

Dito isso, este estudo que ora se apresenta justifica-se por reconhecer a educação como um elemento primordial na formação do humano. Mas não podemos dar espaço a reflexões ingênuas, destarte, indagamos: E educação alinhada aos moldes do capital servirá de elemento na construção de que sujeito? 
Aliado a isso, é que reforçamos a necessidade de discutir a respeito do ensino remoto em tempo de pandemia no estado do Paraná. O qual apresenta um formato que minimiza a real função social da educação, ou seja, a formação humana integral do sujeito foi transferida às plataformas Classroom, em que os estudantes respondem aos questionários pesquisando a resposta no Google sem o menor conhecimento do conteúdo e, dessa maneira, de acordo com Saviani (2019), as funções intelectuais são transferidas às maquinas. Esse sistema educacional demonstra trazer sérios prejuízos para o desenvolvimento das funções intelectuais, considerando também que o conhecimento historicamente produzido pelos homens deve ser mediado pelo professor, o qual lhe foi atribuído uma outra função, a que nos parece de corretor de gabaritos.

A política educacional que vem sendo implementada visa a nota como elemento capaz de representar a aprendizagem e, para isso, as orientações são no sentido de não permitir notas abaixo da média. Parece que na sede de buscar resultados significativos no ranking escolar apresentado por números, a escola abre mão do conhecimento científico e deixa de lado o trabalho que visa a humanização do sujeito, uma vez que não é qualquer conteúdo que transforma o homem em gênero humano.

Assim, a escola na pretensão de fechar suas metas vem reforçando a desigualdade social que é histórica na educação. O sistema de avaliação conforme o Ofício 040/2020 DEDUC/SEED (s.p) estabelece de que maneira os estudantes serão avaliados no novo formato educacional, levando a entender que os estudantes que não tem condições de acesso as mídias online em relação aos que tem, podem ser prejudicados pedagogicamente, uma vez que não terão condições de assistir as aulas postadas. As atividades impressas demonstram partir da esfera da minimização do conhecimento, uma vez que sem a mediação entre professor e aluno essas atividades esvaem-se. Por isso, a solução encontrada pela escola é minimizar o saber do aluno, no sentido de facilitar o conteúdo para que não fique com nota abaixo da média. 


\section{Materialismo histórico-dialético: Contextualizando o estudo}

A teoria social de Karl Marx (1818-1883), associada à questão do método, é apresentada como um complexo de problemas que não advém apenas dos estudos de natureza teórica ou filosófica, porém parte da relação sujeito/objeto e objeto/sujeito. Ela representa a dinamicidade de um projeto revolucionário, em que o sentido de revolução se encontra intrínseco num processo que analisa, de maneira crítica, a sociedade na qual estamos inseridos. Essa teoria é resultado de um longo período de pesquisas e investigações e foi pensada por Marx (1998) como um instrumento de intervenção social, através do método que busca pensar e problematizar a sociedade por um viés político e transformador.

O autor não foi um submisso servidor da burguesia, colocou sua vida e obra a serviço da verdade, dos trabalhadores e da revolução socialista. Somente após 40 anos de estudos, suas ideias resultaram nas bases de sua teoria social. Marx ocupou-se com o estudo da sociedade burguesa desde meados de 1840 até a sua morte. Esse trabalho derivou na definição dos elementos que compõem o método, os quais aparecem na Introdução à Crítica da Economia Política (2008), obra considerada como o princípio dos estudos econômicos de Marx. Tal escrito é composto por elementos como: produção, troca e consumo; método da economia política; meios de produção e relações de produção e relações comerciais; formas de estado e de consciência em relação com as relações de produção e de comércio; relações jurídicas e relações familiares.

Por meio do estudo desses elementos, evidenciam-se as categorias básicas do Materialismo Histórico-Dialético, que apresentam bases teóricas metodológicas para os estudos de Marx, centrados na Economia, uma vez que Marx entendia que as bases filosóficas, por si mesmas, não permitiam analisar a realidade apresentada nas bases materiais. É importante destacar que o autor se dedicou à compreensão da constituição da sociedade burguesa, a qual se debruçou priorizando a categoria da totalidade, analisando a constituição de 
tal sociedade em todas as suas determinações. "[...] a totalidade dessas relações de produção constitui a estrutura econômica da sociedade, [...]. (MARX, 2008, p. 47).

Indo além, é possível compreender porque as relações de produção sustentam a superestrutura, a qual mantém a desigualdade social. Desigualdade esta que é histórica em nosso país, porém em tempo de pandemia tem-se instalado de forma desumana, contribuindo para o aumento da pobreza e para o número de crianças fora da escola.

A infraestrutura que se estabelece na divisão do trabalho, ou seja, a forma antagônica do processo social de produção, situada nas bases reais de vida, é que permite compreender o materialismo de Marx.

As relações materiais dos homens com a natureza constituem-se em um processo independente de consciência, em que os conceitos tais como: sociedade, formações socioeconômicas, estrutura social, organização política da sociedade, cultura, concepção de homem, progresso social etc., são considerações cabais no intuito de compreender o movimento do materialismo histórico, bem como também, os meios de produção e as forças produtivas que delineiam esse movimento, considerando que as formas materiais de existência, tanto podem contribuir para a transformação do homem em gênero humano, quanto para a sua própria alienação. Para Marx (2008, p. 47) “[...] na produção social da própria existência, os homens entram em relações determinadas, necessárias, independentes de sua própria vontade; essas relações de produção correspondem a um grau determinado de desenvolvimento de suas forças produtivas materiais".

O método de Marx atinge o seu ápice ao analisar a economia política de uma determinada população, observando as classes que as compõem e onde essas classes estão estabelecidas: no campo, na cidade, na orla marítima, etc., e os diferentes ramos da produção e as diferentes categorias. Isso faz com que sua teoria se distancie da análise de população dos economistas clássicos, pois entende que a análise da população necessita ser aprofundada. 
Para o autor, o método científico exato é a condição de análise dos objetos constituídos em sua totalidade, em sua materialidade, considerando o histórico e a unidade dos elementos mesmo na sua contradição. O concreto é concreto porque representa a síntese do pensamento como resultado, as determinações abstraídas são conduzidas à reprodução do concreto pelas vias do pensamento, que retorna ao objeto abstrato, mas como uma nova perspectiva de análise do objeto, em que, da totalidade, foram abstraídas as determinações que identificam os tributos que interferem a unidade do diverso. Nesse momento é que acontece a viagem de modo inverso.

Ao estudar a composição da sociedade burguesa, Marx (2008) entende o quanto a mesma é organizada, no que se refere ao sistema de produção, no entanto existem algumas contradições, no que diz respeito à análise do objeto em relação à categoria, numa situação em que,

[... a anatomia do homem é a chave para a anatomia do macaco. O que nas espécies animais inferiores indica uma forma superior não pode ser compreendido [...] senão quando se conhece a forma superior. A economia burguesa fornece a chave para a economia da antiguidade etc. (MARX, 2008, p. 264)

Esta argumentação de Marx apresenta-se na contramão do que é posto pela teoria positivista, no sentido de que o mais simples explica o mais complexo "somente quando uma forma mais complexa se desenvolve e é conhecida é que se pode compreender inteiramente o menos complexo - é o presente, pois que esclarece o passado." (NETTTO, 2011, p. 48). Os estudos realizados a respeito da sociedade burguesa, centrados no positivismo, identificam que a mesma analisa o objeto em decorrência do todo para as partes, ou seja, do geral para o particular (simples para o complexo). Diante da análise do objeto proposto, do geral para o particular, não se negligencia a necessidade de conhecer a origem histórica que compõem uma categoria, tal conhecimento é extremamente necessário e essencial. Porém, ao reportar-se à origem da história, não quer 
dizer que o conhecimento relevante venha centrar-se no presente no sentido de que,

[...] ambos, estrutura e função, podem apresentar característica inexistentes ou atrofiadas no momento da sua emergência histórica. Assim, as condições da gênese histórica não determinam o ulterior desenvolvimento de uma categoria. Por isso mesmo, o estudo das categorias deve conjugar a análise diacrônica (da gênese e desenvolvimento) com a análise sincrônica (sua estrutura e função na organização atual). (NETTO, 2011, p. 49).

Não é correto classificar as categorias em relação as suas ações determinantes, todavia é importante analisar os processos diacrônico e sincrônico no desenvolvimento do estudo das categorias, em uma ação que a análise diacrônica considere o desenvolvimento histórico desde a sua gênese, enquanto que a sincrônica analise a categoria em sua estrutura atual. Diante disso, notamos a relevância da análise do histórico como processo, sem perder de vista a organização atual da conjuntura histórica.

Nessa direção, devemos considerar o estudo existente entre a anatomia do homem em relação à anatomia do macaco, bem como, não deixando de considerar, também, o processo histórico em relação à economia burguesa e à economia da antiguidade. No entanto, a análise consiste num processo mais profícuo e profundo, visto que, "não se trata da relação que as relações econômicas assumem historicamente na sucessão das diferentes formas de sociedade [...] trata-se da sua hierarquia no interior da moderna sociedade burguesa." (NETTO, 2011, p. 50). Para Marx a burguesia permite a articulação com todas as sociedades esvanecidas, sobre as quais sente-se edificada e fortalecida e, assim, a economia política possibilita o estudo da anatomia da sociedade burguesa.

Dessa forma, é possível distinguir que a consciência é categoria primordial para compreender a sociedade burguesa, em que a matéria engendrada a um processo histórico e dialético concebe o mundo num movimento real das coisas " [...] a consciência é, portanto, de início, um produto social e o será enquanto existirem 
homens [...]". (MARX; ENGELS, 1998, p. 25). A consciência remete-se à reflexão da imagem objetiva, surgindo conceitos e representações. É importante que saibamos que o cérebro, em si, não pensa, a consciência está ligada à realidade da matéria.

Marx (2008) estudou as categorias inseridas na população burguesa, ou seja, a produção e distribuição, a troca e consumo, a distribuição de renda, a troca e circulação, movimentam-se de acordo com a realidade em que cada uma delas se pautam, considerando o processo histórico, e não somente a gênese da história, ou seja, considera o movimento da história como um processo. Fato este que ao nos depararmos com os documentos oficiais que orientam o ensino remoto no estado do Paraná não percebemos a importância atribuída a historicidade, a cultura, enquanto co-responsáveis nesse modelo de educação.

No intuito de continuar esclarecendo a categoria da totalidade, do movimento e do histórico, Marx por volta do ano de 1845, elaborou a sua crítica à filosofia alemã dizendo que não é suficiente considerar a matéria estática, uma vez que o movimento dialético da totalidade é imprescindível para a compreensão do objeto para além do abstrato formatado somente no âmbito do pensamento. Marx (1998) avança em relação à crítica posta ao jovem hegeliano Ludwig Feuerbach, posto que, para Feuerbach, não existia interação entre sujeito e realidade, desconsiderando as necessidades reais de pessoas reais, a realidade era apenas contemplação e não atividade humana como práxis.

Dando ênfase na necessidade do desenvolvimento da atividade humana, Marx (2008, p. 262) destaca que "[...] o trabalho é uma categoria tão moderna como o são as condições que engendram essa abstração". A categoria trabalho necessita ser vista como atividade essencial no processo de humanização.

Para Galvão; Lavoura e Martins (2019, p.48)

Mediante o trabalho, portanto, os seres humanos constituem a sua existência. Produzir sua existência significa produzir a si mesmo, se autoproduzir como resultado de sua própria atividade. Esse é o processo histórico de 
produção da humanidade. O desenvolvimento do ser social possibilita, de maneira cada vez mais complexa, o processo de humanização dos sujeitos. Quanto mais o indivíduo se torna social - socialmente desenvolvido -, mais se humaniza. Destaca-se, dessa maneira, uma característica determinada pela atividade fundante do trabalho: a prerrogativa humana de fazer história, de ser sujeito da história, de ser essencialmente produto e produtor de historicidade.

\section{Sistematizando a educação em tempo de pandemia}

A COVID-19, doença causada pelo novo agente do Coronavírus (SARS-CoV-2), desencadeou no ano de 2020 uma pandemia de escala mundial. Devido à sua condição de vírus, em que a transmissão acontece por meio de contato interpessoal, houve a necessidade do emprego de diversas medidas para o controle de sua proliferação. Dentre elas, instituições de ensino brasileiras de todos os níveis passaram a utilizar o ensino remoto ${ }^{1}$ para a execução de suas atividades, de modo a colaborar com o isolamento social.

Diante desse contexto, o estado do Paraná com o objetivo de aderir o isolamento social nas instituições de ensino e evitar o contágio, deliberou que as aulas no formato presencial fossem cessadas e um novo formato de aula não presencial foi apresentado pela SEED, implantando o ensino remoto em todas as escolas públicas e privadas. O estado cumpriu, no ano de 2020, com aulas presenciais até o dia 19 de março, a partir do dia 20 até o dia 03 do mês de abril foi decretado recesso escolar de acordo com a orientação número 04/2020 SEED/DPGE/DLE/CDE (s.p) “para o período de 20/03/2020 a 03/04/2020, registrar no Livro Registro de Classe Online (LRCO) no dia 20/03/2020, "Sem Atendimento Pedagógico" e no campo “Observações” Recesso Escolar. Dec. 4258/2020.”

Modo de ensino temporário e não presencial empregado durante a pandemia da COVID-19. Segundo a Instrução Normativa nº 001/2020 da Secretaria de Educação do Município de Cascavel/PR, trata-se de "aulas não presenciais, planejadas e elaboradas pelo (a) professor (a) aos alunos matriculados regularmente na Rede Pública Municipal de Ensino de Cascavel, nas Etapas da Educação Infantil e do Ensino Fundamental - Anos Iniciais [...]” (art. $1^{\circ}$, caput). 
A contar do dia 06.04 começamos a registrar as aulas normalmente. Porém, nesta data as turmas online na plataforma Google Classroom ainda não haviam sido criadas.

A partir desse cenário, tem-se como objetivo discutir as orientações pedagógicas para as atividades avaliativas, concedidas pela SEED, no que se refere ao ensino remoto. De acordo com o Ofício 040/2020 DEDUC/SEED (s.p),

[...] como e de que forma vou avaliar os meus alunos? Antes de planejar as diferentes formas de avaliar, é fundamental levar em consideração a forma de participação e acesso dos estudantes nas aulas: 1) Estudantes com acesso a todas as ferramentas disponíveis (aulas exibidas na TV aberta, You'Tube e Google Classroom) - Neste caso, o professor possui maiores possibilidades de propor avaliações diversificadas [...]

2) Estudantes que apenas conseguem assistir as aulas na TV aberta - Neste caso, os estudantes poderão ser avaliados pela resolução das atividades propostas durante a explicação do professor. Inclusive, são disponibilizados minutos cronometrados para que reflitam e resolvam os exercícios e questionamentos apresentados nas videoaulas. Essas atividades deverão ser entregues na escola de 15 em 15 dias. Elas serão encaminhadas aos professores para correção, que validarão o registro da frequência e da nota. A escola pode disponibilizar o material impresso de acordo com as aulas já trabalhadas. Este material deve ser organizado com questões contextualizadas, conforme a realidade de cada aluno. 3) Estudantes que não possuem acesso à TV aberta e à internet - Neste caso, os estudantes serão avaliados por meio das atividades impressas, as quais estão sendo entregues, a cada 15 dias, aos responsáveis. A escola pode, ou não, utilizar as atividades enviadas pela SEED e/ou adequá-las de acordo com suas especificidades e nível de aprendizagem de seus estudantes. 4) Estudantes que, por algum motivo, não estão conseguindo realizar as atividades não presenciais, nem mesmo as impressas - Neste caso, no retorno das aulas presenciais, deverá ser realizado um estudo dirigido, com os objetivos de aprendizagem e as atividades abordados durante o $1^{\circ}$ trimestre nas aulas não presenciais. Se necessário, ainda, estes estudantes deverão participar de estudos dirigidos e do Programa Mais Aprendizagem (se a escola ofertar), além de ter parceria do Aluno Monitor. A escola também deve solicitar ao NRE adequação do registro das notas do $1^{\circ}$ trimestre para que nenhum desses estudantes seja prejudicado ou excluído do processo avaliativo. Grifos nossos. 
Vale esclarecer que é compreensivo o momento atípico devido à pandemia, bem como a necessidade do isolamento social que fez com que a Secretaria de Educação do Estado reconfigurasse o formato da educação. O que nos parece que não é compreensivo, de acordo com o citado, acima são as várias formas de realizações avaliativas de acordo com as condições de acesso de cada aluno à plataforma Google Classroom. Dá maneira como está expressa a realização das atividades avaliativas no referido ofício, nos parece que o estudante com maior possibilidade de acesso às mídias online terá também maior possibilidade de apropriação do conteúdo, isso quer dizer, quanto menos possibilidade de acesso à plataforma online, menos possibilidade de apropriação do conteúdo.

Diante disso, nos perguntamos: É possível mencionar aprendizagem nesse formato de ensino com tantas disparidades na realização das atividades avaliativas? Sabe-se que as escolas têm sido cobradas pela quantidade de acessos dos alunos à plataforma online, demonstrando assim que é por meio desta quantidade que se considera a eficácia desse modelo educacional. Reiteramos que uma educação para todos, como é a defesa do referencial adotado para o desenvolvimento desse estudo, pauta-se na qualidade do processo educativo e não na quantidade, nos resultados.

O Professor nesse novo formato de educação passou de mediador do conhecimento historicamente acumulado para corretor de gabarito ou tirador de dúvidas.

O Comunicado $n^{\circ}$ 07/2020 - CDE/DLE/DPGE/SEED (s.p) traz que,

Os professores das Escolas Estaduais Indígenas que utilizam apenas atividades dirigidas impressas farão o registro da frequência dos estudantes das aulas referentes a conteúdos que forem possíveis de serem realizados nesse formato. No campo "Observação da turma”, registrar: os conteúdos que só podem ser trabalhados presencial serão abordados no retorno das atividades presenciais. Grifos nossos. 
O excerto acima reforça a desigualdade instalada na maneira de se trabalhar o conteúdo aos estudantes que não tem acesso às mídias online. O que podemos analisar nesse novo formato de educação é que as famílias desprovidas do capital mais uma vez são atiradas à margem social, principalmente os povos indígenas, os quais permanecem excluídos e com seus direitos blindados apenas no papel. Assim, como os povos indígenas, nossa sociedade é repleta de exclusões e as políticas educacionais no âmbito do neoliberalismo têm auxiliado a avolumar a esfera da injustiça e da desigualdade social.

As Diretrizes Curriculares Nacionais da Educação Básica (DCNEB, 2013) mencionada no Referencial Curricular do Paraná (2018), salienta que as práticas pedagógicas visem a promoção da equidade, reconhecendo a singularidade dos estudantes. Compreendemos que o documento destaca a promoção da equidade também em relação aos povos indígenas, no entanto, ao analisar a prática pedagógica direcionada a esses alunos é notável que a promoção da equidade só reforça o hiato existente entre o discurso e a realidade.

[...] empreendendo esforços para cumprir o compromisso de reverter a situação de exclusão histórica que marginaliza grupos - como os povos indígenas originários e as populações das comunidades remanescentes de quilombos e demais afrodescendentes - e as pessoas que não puderam estudar ou completar sua escolaridade na idade própria. Igualmente, requer o compromisso com os alunos com deficiência, reconhecendo a necessidade de práticas pedagógicas inclusivas e de diferenciação curricular. (BRASIL, 2013. p. 15). Grifos nossos

O ensino remoto no formato proposto não visa a singularidade do aluno nos aspectos, cognitivo, econômico, social e cultural. A população indígena continua refém de uma desigualdade marcada pela barbárie e pelo obscurantismo.

Nesse sentido, o ensino remoto proposto pelo Estado do Paraná na Educação Básica não leva em consideração a materialidade da vida concreta do indivíduo, uma vez que, as atividades escolares passam a ser realizadas por meio de mídias online, aqueles que não possuem tais mídias (celular, notebook, computador, internet, 
etc.) não farão parte dos pacotes de aulas projetados. Irão participar com as atividades impressas, ou seja, responderão alguns questionários, a maioria de múltipla escolha, sem ter acesso a nenhum tipo de mediação do conteúdo pelo professor.

A educação brasileira já marcada por um longo processo histórico de desigualdade social, reforça suas características através do ensino remoto, uma vez que não há acesso de todos. Nesse modelo educacional, a história de vida concreta do sujeito não justifica sua não possibilidade de acesso as atividades escolares. A desigualdade social passa a ser naturalizada e nos parece, pelo que se apresenta, tornando a educação num imenso faz de conta. O professor faz de conta que ensina, porque diante da precarização do seu trabalho isso não é mais possível, e o aluno faz de conta que aprende.

Saviani (2019, p. 333) enfatiza que

A "Revolução da Informática", "Revolução Microeletrônica", ou "Revolução da Automação”, vêm provendo a transferência não apenas das funções manuais para as máquinas, como ocorreu na Primeira Revolução Industrial, mas vêm transferindo as próprias funções intelectuais para as máquinas.

No contexto atual, o ensino remoto tem como sinônimo de aprendizagem a plataforma Google, a qual é explorada pelos estudantes como um centro de pesquisa que traz respostas as dúvidas, no entanto, não desenvolve o conhecimento. Nesse formato de "ensino" as funções intelectuais estão sendo engessadas em nome de educação fabricada pelo capital. Desse modo, a educação em tempo de pandemia no estado do Paraná, apresenta-se transvestida de qualidade e superação, enquanto que, na realidade tem sido uma máquina algoz contra a verdadeira função da escola. Serve com satisfação o princípio capitalista, cujo o maior interesse está impresso no sucesso da máquina e na alienação do trabalhador.

A escola construída nos moldes capitalistas não apresenta possibilidade de transformação do homem em gênero humano o que implica num formato educacional que não ultrapassa o limite da alienação. 
Para enfatizar o processo de alienação do sujeito, Saviani (2019) salienta que na Primeira Revolução Industrial os trabalhadores compreenderam que poderiam se libertar dos trabalhos pesados, no entanto, esse processo acirrou-se quando os proprietários das máquinas fizeram o trabalhador seguir o ritmo alucinantes das máquinas, empreendendo toda sua energia.

Nesse sentido,

Atualmente ocorre um processo semelhante. O advento das novas tecnologias acena como possibilidade de libertação de praticamente todo tipo de trabalho material, ampliando sem precedentes a esfera do tempo livre e colocando-nos, portanto, no limiar do "reino da liberdade". No entanto, assim como as máquinas mecânicas, também as máquinas eletrônicas são introduzidas no processo produtivo sob a forma de propriedade privada dos capitalistas. (SAVIANI, 2019, p.336).

Defendemos que a educação deve ser amparada por um projeto educacional que vise a humanização do homem, no entanto, esse ensino proposto decorre da realização de atividades que retira do professor a autonomia de ministrar suas aulas, transformando o ensino em algo a ser cumprido, sem reflexão e sem crítica, não levando em consideração a dialética do pensamento.

A educação remota sem a mediação do professor minimiza às possibilidades reais do conhecimento, fragilizando as condições de compreensão da realidade, ou seja, esse modelo educacional não oferece ao aluno possibilidades de perceber o mundo e a internalização das suas múltiplas relações.

O Materialismo Histórico-Dialético expressa que o conhecimento é

[...] resultado do processo humano de domínio, apropriação e transformação da natureza. Ao entrar em relação com a natureza e, por meio do desenvolvimento cada vez mais apurado da consciência, organiza conteúdos de pensamento cada vez mais complexos sobre a realidade, em um processo crescente e interminável. Para que o conhecimento esteja inserido nos pressupostos da dialética materialista, é importante que ele seja 
compreendido como enraizado na realidade, produzido pelos indivíduos, para os indivíduos e com os indivíduos. (GALVÃO; LAVOURA; MARTINS, 2019, p. 54).

Dessa maneira, o ensino implementado no ano letivo de 2020, denota dificuldades de oferecer possibilidades de elevar o pensamento do aluno ao concreto pensado, negando a produção do conhecimento crítico e fortalecendo a reprodução.

Assim a educação

[...] moldada caprichosamente pelos interesses capitalista, está representada como fantoche nas mãos do poder, em que a produção intelectual, ou seja, a apropriação de conhecimento científico que poderia ser elementos notáveis versus a conservação, não passa de um amontoado de conteúdos organizados no senso comum, extraindo da educação o importante papel na construção de subsídios, que amparam o desenvolvimento do processo consciente no ser humano. Dessa maneira, fica renegado à consciência a compreensão do processo de transformação [...] (MARCHI; ROSSETTO, 2018, p. 280).

O terceiro princípio citado no Referencial Curricular do Paraná (2018, p.10)² expressa: "Igualdade e Equidade, no intuito de assegurar os direitos de acesso, inclusão, permanência com qualidade no processo de ensino-aprendizagem, bem como superar as desigualdades existentes no âmbito escolar”. E na p.15:

[...] a existência de condições desiguais de oferta da educação aos estudantes, que se configuram em violações de direitos constitucionais, reforçando as desigualdades socioeconômicas, étnico-raciais e regionais. Para que esta realidade seja transformada, é importante considerar a escola como espaço em que a igualdade e a equidade possam constituir valores essenciais para a formação dos sujeitos, e por sua vez, apontem elementos para a construção de políticas públicas voltadas para a promoção da justiça social. A busca da equidade requer a oferta de

O Referencial Curricular do Paraná: princípios direitos e orientações (2018), entrou em vigor no início do ano letivo de $2020 \mathrm{em}$ todas as instituições escolares do Paraná (Educação Infantil e Ensino Fundamental). 
mais recursos, melhores condições às escolas menos providas e aos estudantes que mais necessitam, [...]. Grifos nossos.

A desigualdade de acordo com Saviani (2019, p. 339) “[...] é a triste marca de nossa tradição histórica", vem sendo reforçada com o formato educacional remoto em tempo de pandemia. "A meta de garantir a todas as nossas crianças a desejada igualdade de acesso aos bens culturais" (SAVIANI, 2019, 339), tem se esvaído diariamente na educação online, a qual simplesmente trabalha em busca de resultados. A igualdade e a equidade interpelada no documento acima, são adjetivos adotados para a educação. Partem de uma realidade que não considera a desigualdade social, uma vez que igualdade e equidade não são conceitos a serem equiparados numa sociedade dividida em classes sociais.

Dessa maneira, o discurso de uma educação remota bem sucedida, não ultrapassa a realidade vazia e descontextualizada que estamos vivenciando, a qual substituiu o processo de ensino e aprendizagem por um rol de números e resultados divulgados por notas acima da média, atribuída de maneira indevida para provar o sucesso desse novo formato educacional que apresenta o suicídio do conhecimento.

Diante disso, quando o conhecimento não é elevado a sua forma mais complexa, não propicia condições "para o povo se transformar de súditos em cidadãos, isto é, para ser capaz de governar ou de eleger e controlar quem governa, deve ser educado". (SAVIANI, 2019, p.344). Assim, ao nosso ver, o ensino remoto implantado no estado do Paraná reforça a construção do sujeito unilateral e acentua uma educação no formato de atender os princípios do capital, nos quais a desigualdade social é reverenciada.

De acordo com Dias e Pinto (2020, s.p.).

A Educação a distância (EaD) não pode ser a única solução, esta metodologia tende a exacerbar as desigualdades já existentes, que são parcialmente niveladas nos ambientes escolares, simplesmente, porque nem todos possuem o equipamento necessário. Se a meta for investir apenas 
em ferramentas digitais, certamente, contribuiremos para uma piora na aprendizagem dos alunos a curto e a médio prazos. Na pandemia, grande parte das escolas e das universidades estão fazendo o possível para garantir o uso das ferramentas digitais, mas sem terem o tempo hábil para testá-las ou capacitar o corpo docente e técnico-administrativo para utilizá-las corretamente. Há ainda outros obstáculos graves, especialmente para alunos e professores mais empobrecidos, muitos deles localizados na periferia das grandes cidades ou na zona rural. Faltam computadores, aparelhos de telefonia móvel, software e internet de boa qualidade, recursos imprescindíveis para uma EaD que resulte em aprendizagem.

A partir dessa fala fica claro a preocupação para além da aprendizagem do aluno, mas também com a realidade de todos os alunos, suas condições culturais, sociais e principalmente econômicas. O ensino remoto precisa ser pensado e implantado considerando-se o acesso daqueles que dela farão uso, e com qualidade. Fato este que nos parece não acontecer com boa parte dos sujeitos das escolas públicas.

Stevanim (2020, p.14) ressalta que

O cenário da educação brasileira na pandemia é de "uma crise dentro da crise", na avaliação de Andressa Pellanda, coordenadora geral da Campanha Nacional pelo Direito à Educação. Segundo ela, as desigualdades estruturais "emergiram à superfície nesse momento de pandemia". "As políticas adotadas para a educação, como a implantação de educação remota mediada por tecnologias, foram pensadas de forma alheia a essa desigualdade, sem trazer caminhos de solução dos problemas estruturais. E elas não deram certo", avalia. Em um momento em que se exige a manutenção dos estudos em casa, estudantes brasileiros convivem com problemas de saneamento e acesso a água e alimentos, ausência de um ambiente de qualidade para estudos e falta de apoio dos pais e responsáveis, que por vezes também não tiveram.

Portanto, pode-se dizer que a educação remota para as escolas públicas do estado do Paraná desde a sua vigência estabeleceu várias medidas a serem adotadas a partir do uso de tecnologias, no entanto, desconsiderando que muitos dos alunos historicamente neste país passam por dificuldades para suprir suas necessidades 
básicas, o que os impede de investir em tecnologia. Os homens para construir sua história necessitam viver e, para viver é necessário ter condições, ou seja, condições materiais. O primeiro fato histórico é a produção de condições para manter-se vivo na construção da história, "produção da própria vida material" (MARX; ENGELS, 1998, p.21).

\section{Considerações finais}

Com base no estudo realizado, e de acordo com o que temos vivenciado através do ensino remoto no estado do Paraná adotado desde o mês de abril de 2020, as políticas públicas educacionais que norteiam a educação não consideram o princípio da totalidade no que se refere ao saber elaborado cientificamente e ao papel do professor. Nos parece sim que essa totalidade é constituída por partes. Como nos traz Netto, (2011, p. 56): Para Marx "[...] Não é um "todo" constituído por "partes" funcionalmente integradas. Antes, é uma totalidade concreta inclusiva e macroscópica, de máxima complexidade". Bem como, essa política não tem demonstrado esforços para respeitar o princípio da igualdade de direitos, já que adotou um ensino do qual muitos não têm acesso.

Assim, podemos dizer que o que estamos vivenciando no campo educacional desconsidera os aspectos históricos, sociais, culturais e econômicos do aluno. Fato este que se contrapõe ao Materialismo Histórico-Dialético. Bem como a mediação do conhecimento apresenta-se fragilizada, visto que, entre inúmeros outros motivos, o mais gritante, é a desigualdade de oportunidades em relação ao uso das mídias online. A mediação que visa números e resultados quantitativos, não é a mesma que visa o processo de humanização do sujeito. O conhecimento deve ser mediado, com o objetivo de identificar os elementos naturais e socioculturais a serem apropriados pelos sujeitos da espécie humana para que possam tornar-se humanos. Defendemos que essa mediação no campo educacional se dê através da figura do professor.

Nessa perspectiva o conhecimento é o elemento principal na construção da vida consciente e coletiva do indivíduo, o qual 
compreende que a transformação do homem, em gênero humano, depende da formação da consciência articulada às bases da vida real e das condições materiais do sujeito. $\mathrm{E}$ isso, com a modalidade de ensino remoto parece não se efetivar. Entendemos que o conhecimento é resultado de um longo processo de apropriação e transformação da natureza, num movimento dialético. Para o marxismo, “[...] o método é de grande importância, pois só por meio dele é que conseguimos ir além das aparências das coisas, [...]”. (GALVÃO; LAVOURA; MARTINS, 2019, p. 63). E aqui, entre inúmeros outros elementos, estamos considerando a metodologia que se tem adotado em tempo de pandemia nas instituições escolares, que se distancia do proposto por Marx.

Diante do exposto, é possível concluir que a educação que reforça a desigualdade social, utilizando-se de metodologias pedagógicas e instrumentos midiáticos que nem todos tem acesso, não está preocupada com a formação humana integral do sujeito. Ou seja, o ensino remoto implantado no estado do Paraná nesse formato apresenta uma maneira desigual de atendimento, primando pelo aligeiramento e fragmentação, impedindo a autonomia do aluno no que diz respeito a apropriação do conhecimento, com vistas a um sujeito crítico, ativo, autônomo. Assim como peca violentamente quanto ao papel do professor, às tarefas a ele atribuídas.

Portanto, podemos dizer que a educação remota implantada rompe definitivamente o laço entre a educação e a ciência ao encaminhar um sistema de avaliação escolar que visa a nota, o resultado final e não o processo, a aprendizagem e transfere à máquina nomeada (Google ) a função da mediação do conhecimento. Nota-se que a cientificidade do conhecimento não é a característica desse ensino, visto que a qualidade foi substituída pela quantidade de atividades a serem realizadas principalmente por parte dos professores.

Nesse sentido, a educação não supera a visão confusa e sincrética do fenômeno estudado, reforça apenas seus aspectos elementares. Defendemos que as mediações realizadas no âmbito escolar necessitam romper com a representação caótica do todo para 
alcançar o conhecimento das determinações que transformam o concreto em concreto do pensamento e, dessa maneira, tornar o homem em gênero humano, respeitando sua singularidade nas esferas: histórica, cultural, social e econômica.

Assim, pautados no referencial teórico norteador desse estudo, concluímos que a educação remota Paranaense, parece não apresentar como objetivo o desenvolvimento do processo humano de domínio do conhecimento, o que torna difícil a construção da consciência em sua forma mais elaborada, negando ao indivíduo uma concepção de mundo que permita compreender a realidade a qual está inserido e o lugar que ocupa nesta sociedade dividida em classes. O ensino remoto nesse caso, com suas plataformas online denota reforçar a constituição do sujeito nos princípios da alienação.

E, finalmente dizer que a "atualização" da educação aos moldes do que tem sido proposto pelas políticas educacionais na sociedade capitalista promove uma formação unilateral direcionada para o trabalho e para o consumo. As orientações para o trabalho docente são coerentes com a formação do homem esperado para a reprodução das condições vigentes no âmbito do capitalismo dependente. (Marx, 2008)

\section{Referências}

BRASIL. Ministério da Educação. Conselho Nacional de Educação; Câmara de Educação Básica. Diretrizes Curriculares Nacionais da Educação Básica. Brasília: MEC; SEB; DICEI, 2013.

DIAS, E; PINTO, F. C. F. A Educação e a Covid-19. Revista Ensaio: avaliação e políticas públicas em Educação, Rio de Janeiro, v.28, n.108, jul/set. 2020. Disponível em: 26 fev. de 2021.

GALVÃO, A. C; LAVOURA, T. N; MARTINS, L. M. Fundamentos da Didática Histórico-Crítica. $1^{\text {a }}$ ed. Campinas, SP: Autores Associados, 2019.

MARCHI, S. C; ROSSETTO, E. Marx e Engels, Durkheim e Bourdieu: contribuições para compreender a relação entre educação e sociedade. Nuances: estudos sobre educação, Presidente Prudente - SP, v29, n. 1, p. 274-289, jan/abril, 2018. 
MARX, KARL. Contribuição à Crítica da Economia Política. [Tradução e Introdução Florestan Fernandes]. São Paulo: Editora Expressão Popular, 2º Ed. 2008.

MARX, K; ENGELS, F. A Ideologia Alemã. [Introdução de Jacob Gorender]. Tradução: Luís Claudio de Castro e Costa. São Paulo: Martins Fontes, 1998.

NETTO, J. P. Introdução ao Estudo do Método de Marx. São Paulo: Expressão Popular, 2011.

ORSO, P. Neoliberalismo: equívocos e consequências. In: LOMBARDI; SANFELICE (Org.). Liberalismo e educação em debate. Campinas, São Paulo: Autores Associados, Hístedbr, 2007.

PARANÁ. Secretaria de Estado da Educação e do Esporte. Comunicado 007/2020 - CDE/DLE/DPGE/SEED. Informações complementares para os registros de frequência, conteúdos e avaliações no LRCO. SEED: Curitiba, 2020.

PARANÁ. Secretaria de Estado da Educação e do Esporte. Ofício Circular 040/2020 - DEDUC/SEED. Planejamento de avaliações durante a pandemia do Covid-19. SEED: Curitiba, 2020.

PARANÁ. Secretaria de Estado da Educação e do Esporte. Orientação 04/020 SEED/DPGE/DLE/CDE. Orienta sobre os registros no Livro Registro de Classe Online - LRCO para a Rede Estadual de Ensino do Estado do Paraná para o período de enfrentamento ao surto do novo Coronavírus (COVID-19). SEED: Curitiba, 2020.

PARANÁ. Secretaria de Estado da Educação. Referencial Curricular do Paraná: princípios, direitos e orientações. Educação Infantil e Componentes Curriculares do Ensino Fundamental. SEED: Curitiba, 2018.

SAVIANI, D. Pedagogia Histórico-Crítica, quadragésimo ano: novas aproximações. Campinas, SP: Autores Associados, 2019.

STEVANIM, L.F. Desigualdades sociais e digitais dificultam a garantia do direito à educação na pandemia. Exclusão nada remota. Radis n.215, ago. 2020. Disponível em: 26 fev.de 2021.

Submetido em: 23-10-2020

Aceito em: 24-7-2021 